\title{
ПРИМЕНЕНИЕ ИНТЕРАКТИВНЫХ ТЕХНОЛОГИЙ В ОБУЧЕНИИ ГЕОГРАФИИ И ИНОСТРАННОГО ЯЗЫКА В ШКОЛЕ
}

\section{APPLICATION OF INTERACTIVE TECHNOLOGIES IN TEACHING GEOGRAPHY AND A FOREIGN LANGUAGE AT SCHOOL}

\section{Akhmetova}

R. Galiev

Summary: The article is devoted to the effective use of interactive technologies in teaching geography and a foreign language at school. The main task of the author is to show the importance of interactive technologies in the formation of research and project skills, organization of reflection, communication, which determines the competence of a modern student. Examples of the introduction of interactive learning in the educational process, in particular in geography and foreign language classes, are presented. In the process of the research, methods of generalization, analytical and synthetic activity, and modeling were used. The authors note that the preparation and conduct of lessons using innovative technologies and methods requires certain skills and training of the teacher, the ability to work with students in non-standard conditions and situations.

The article shows the importance of interactive learning in increasing cognitive activity and educational interest, activating search activity, and striving for practical actions, as a result of which learning becomes more conscious and purposeful.

Keywords: education, pedagogy, geography lessons, foreign language lessons, interactive, technology, learning, cognitive activity, communication, independence, interaction, motivation, efficiency, students, reflection.
$\Phi$ едеральный государственный образовательный стандарт предъявляет высокие требования к современному школьному обучению. Большие объемы информации, изучаемые за короткие промежутки времени, а также повышенные требования к уровню знаний и умений обучающегося являются реалиями современного образовательного процесса [7; 12].

Интерактивные технологии обучения способствуют интенсификации процесса понимания изучаемого материала, а также нестандартному использованию знаний на практике. Активное внедрение учеников в процесс получения и использования знаний способствует повышению эффективности образовательного процесса. Регулярное использование различных форм и методов интерактивного обучения формируют прочные навыки

\author{
Ахметова Милауша Хасановна \\ К.с.н., дочент, Набережночелнинский государственный \\ педагогический университет \\ fialka-21@bk.ru \\ Галиев Ракип Рубинович \\ Набережночелнинский государственный педагогический \\ университет \\ rakip.galiev19@gmail.com
}

Аннотация: Статья посвящена вопросам эффективного применения интерактивных технологий в обучении географии и иностранного языка в школе. Основная задача автора - показать значение интерактивных технологий в формировании навыков исследовательской и проектной деятельности, организации рефлексии, коммуникации, что и определяет компетентность современного ученика. Представлены примеры внедрения интерактивного обучения в образовательный процесс, в частности на уроках географии и иностранного языка. В процессе исследования применялись методы обобщения, аналитико-синтетической деятельности, моделирования.

Авторы отмечают, что подготовка и проведение уроков с использованием инновационных технологий и методов требует определенных навыков и подготовки со стороны преподавателя, умения работать с учащимися в нестандартных условиях и ситуациях.

Показано значение интерактивного обучения в повышении познавательной активности и образовательного интереса, активизации поисковой деятельности, стремления к практическим действиям, в результате чего обучение школьным предметам становится более осознанным и целенаправленным.

Ключевые слова: образование, педагогика, уроки географии, уроки иностранного языка, интерактивный, технология, обучение, познавательная активность, коммуникация, самостоятельность, взаимодействие, мотивация, эффективность, обучающиеся, рефлексия.

овладения информацией. При этом отсутствует негативная оценка, обучающиеся не испытывают чувство дискомфорта и страха при выражении своей точки зрения $[5 ; 11]$.

Под интерактивным обучением предполагается такая форма организация познавательной деятельности, при которой все ученики погружаются в процесс познания в условиях высокой самостоятельности и эмоционального комфорта. Каждый участник является ключевым «элементом» системы и вносит свой индивидуальный вклад, делится знаниями и идеями. Интерактивное обучение позволяет раскрыть позицию каждого обучающегося, исключая преобладание одного мнения над другим.

Использование интерактивных технологий позволя- 
ет решать одновременно несколько педагогических задач, а также способствует развитию коммуникативных умений и навыков, что в свою очередь является важным для освоения новых компетенций. Стоит отметить, что применение данной технологии обеспечивает воспитательную задачу, способствует формированию эмоциональных контактов среди обучающихся, а также учит командной работе, акцентирует внимание на важности каждого мнения и идеи, развивает познавательный интерес, фантазию и творческий потенциал, коммуникабельность, активную жизненную позицию, индивидуальность, свободу в самовыражении, взаимопонимание, уважение и демократичность. Работа по интерактивным технологиями обучения помогает снять эмоциональное напряжение обучающихся, открывает для педагога возможности выбора форм деятельности, позволяющие акцентировать внимание на ключевых моментах урока.

Интерактивное обучение способствует повышению познавательной активности и образовательного интереса, позволяющие активизировать поисковую деятельность, побуждает их к конкретным действиям, в результате чего обучение становится более осознанным и целенаправленным. Применение интерактивных технологий позволяет внести вариативность в мыслительный процесс, а именно неординарное видение проблемной ситуации, путей ее разрешения. Также развиваются такие способности как принятие альтернативной точки зрения, партнерство, толерантность по отношению к оппоненту, а также доброжелательность в общении [9].

Для интерактивного педагогического взаимодействия характерна высокая степень коммуникации участников образовательного процесса, предполагающая частые смены видов и форм деятельности, самоанализ своей деятельности во взаимодействии с другими участниками образовательного процесса. В целом интерактивные педагогические технологии направлены на достижение соответствующих моделей поведения обучающихся.

Стоит отметить, что подготовка и проведение уроков с использованием инновационных технологий требует определенных профессиональных навыков со стороны педагога, умения работать с учащимися в нестандартных условиях и ситуациях, что, в свою очередь, усложняет задачу.

При организации интерактивного обучения следует учитывать специфику методов и придерживаться определенных требований. Например, при применении метода проектов, педагогу необходимо создать такие условия, в которых ученик сам выбирает объект исследования, сам решает для себя какие источники информации использовать: ограничиться ли учебником или углубиться в изучаемый материал и прибегнуть к помо- щи более серьезной литературы [3].

При использовании метода кейсов также стоит обращать внимание на особенности организации. Основное требование при работе с кейсами - реальность изучаемых ситуаций. Кейс-метод строится на осмыслении, глубоком анализе и разрешении конкретных ситуаций или проблем (кейсов). Кейс представляет собой описание определенной ситуации, происходящей в реальной жизни или теоретически возможной, содержащую в себе проблему, которую необходимо решить. Эта методика позволяет преподавателю проецировать в учебную аудиторию частичку реальной жизни, воспроизвести практическую ситуацию, которую в свою очередь необходимо обсудить, проанализировать и предоставить обоснованное решение.

Во время реализации интерактивного общения учитель осуществляет управление и контроль данного процесса, используя косвенные приемы педагогического воздействия, что позволяет обучающимся проявлять максимальную самостоятельность в выборе цели, соответствующих действий, а также партнеров по деятельности [9].

В педагогической науке в настоящее время не существует достаточно полной классификации интерактивных технологий обучения. Наиболее удачной считаем классификацию Т. С. Паниной, Л.Н.Вавиловой, подразделяющие интерактивные технологии обучения на три группы: дискуссионные (диалог, групповая дискуссия, разбор ситуаций из практики); игровые (дидактические и творческие игры, в том числе деловые и ролевые, организационно-деятельностные игры); тренинговые (коммуникативные тренинги, тренинги сензитивности) [6].

Разнообразие интерактивных технологий позволяет педагогу эффективно применять их в обучении школьных предметов. Применение интерактивных технологий обучении в школьных курсах географии решает спектр различных образовательных задач, связанных с формированием навыков исследовательской и проектной деятельности, организации рефлексии, коммуникации, что, в конечном счете, с полученными в ходе школьного образования умениями и знаниями определяет компетентность современного ученика.

Например, при изучении темы «Природные зоны мира» прекрасно подойдет такая форма интерактивного обучения, как кейс-метод, которая строится на осмыслении, глубоком анализе и разрешении конкретных ситуаций или проблем (кейсов). Также целесообразно использовать элементы кейса при изучении темы «Население мира» (10 класс).

При составлении ситуационных задач для школьных 
курсов географии целесообразно акцентировать внимание на актуальных проблемах:

- взаимодействие человека и природы;

- разработка туристического маршрута в зависимости от целевой аудитории;

- выбор территории для строительства промышленного предприятия с учетом заданных параметров;

- перспективы развития свободных экономических зон на территории Российской Федерации.

На уроках географии возможно использование метода инцидента: обучающимся предлагается сообщение о происшествии на территории какой - либо страны, организации. Информация сообщается не полностью, в связи с чем обучающимся приходится разбираться в ситуации, анализировать и сопоставлять данные и факты, исходя из этого принимается определенное решение по устранению проблемной ситуации. Основная цель данного метода - научить школьников самостоятельной работе с различными источниками информации, обработке, систематизации и анализу полученных данных [2].

Метод ситуационно-ролевых игр организуется в виде инсценировки перед классом реальной экономической, правовой, исторической, социально-психологической ситуации, позволяющая дать объективную оценку ситуации и поступков учеников.

Разбор деловой корреспонденции (или «информационный лабиринт»), основан на работе со статистическими материалами, документами определенной тематики, организации, ситуации и т.д. У каждого учителя, проработавшего в школе хотя бы 3-5 лет, найдется достаточное количество рефератов и сообщений по изучаемой теме, в которых, как правило, приведены различные факты и статистические материалы об одном и том же явлении или процессе. Именно они могут служить материалом для учебного кейса, а задача учителя - правильно систематизировать материалы и четко поставить цели перед учащимися, прежде чем они приступят к обработке информации и обобщениям.

Метод проектирования представляет собой процесс создания проектов различного типа: исследовательского, поискового, творческого, прогностического, аналитического и др. Это один из эффективных методов, позволяющий учащимся не только обобщить теоретические знания, но и реализовать свои творческие способности, обобщить межпредметные компетенции. В школьных курсах географии, целесообразно организовывать проектную деятельность при изучении отраслей промышленности, ученики могут создавать мини-проекты, направленные на создание различных предприятий по определенным параметрам, а также проекты по освоению месторождений полезных ископаемых, развитию транснациональных компаний, отдельных регионов и стран в целом.

Обучающимся также можно предложить и долгосрочные проекты: к примеру, на уроках географии в 6 классе, в течение всего года обучающиеся разрабатывают модель гипотетического материка, рисуют тематические карты данной территории, воссоздают новые страны, города, прописывают историю открытий и исследований [2].

Из вышеизложенного следует, что интерактивное обучение является более инновационным и эффективным, чем традиционное, способствует повышению мотивации участников в процесс решения поставленных перед ними целей и задач, стимулирует познавательную активность обучающихся к последующей поисковой деятельности. Все эти методы и приемы прививают ученикам самостоятельность, учат принимать важные для себя решения и нести за них ответственность, находить и обрабатывать информацию, не бояться совершать ошибки, помогают почувствовать себя важным и значимым.

Интерактивные технологии также целесообразно использовать в обучении иностранного языка для решения проблемы говорения и устранения языкового барьера.

Например, технология под названием «Аквариум» устроена по типу спектакля, где ученики играют роль зрителей, выступающих в роли наблюдателей, экспертов, аналитиков и критиков. Суть «спектакля» состоит в том, что одни обучающиеся - актеры разыгрывают определенную ситуацию на импровизированной сцене, другие наблюдают и анализируют. При изучении темы «Эмоции и черты характера» можно предложить определенный «аквариумный диалог», при этом текст диалога может быть любым, например, разговор на ресепшене отеля или диалог официанта и посетителя ресторана. Перед обучающимися - актерами ставится задача передать определенное настроение или эмоцию, черты характера, а обучающиеся - зрители, в свою очередь, должны это заметить, объяснить увиденное [10].

Технология «Карусель» представляет собой одну из разновидностей психологических тренингов. Суть данной технологии состоит в том, что обучающиеся образуют два кольца, одно из них внутреннее, другое внешнее. Внутреннее кольцо состоит из сидящих неподвижно учеников, обращенных лицом к внешнему кругу, внешнее кольцо - из обучающихся, перемещающихся по кругу через каждые 30 секунд. За короткий период времени они успевают проговорить несколько тем и склонить к своей точке зрения своего собеседника. Данная технология хорошо подходит для отработки диалогов этикетного характера и может иметь положитель- 
ные результаты при изучении тем: «Национальность», «Разговор в общественном месте», «Знакомство». Стоит отметить высокую динамику и коммуникацию во время занятий с использованием данной технологии [8].

Применение технологии «Незаконченное предложение» предполагает прочтение обучающимся неполного, незаконченного предложения, касающегося различных жизненных сфер, и продолжения его разными словами, приходящими в голову. Неопределенность предложений дает возможность подключить фантазию и творческий потенциал обучающихся [1].

Список использованных технологий можно продолжать бесконечно, стоит также отметить: дискуссии, дебаты, семинары, различные игры. Также существует огромное количество форм ролевых игр на уроках английского языка: презентации, клубы по интересам, интервью, заочные путешествия, круглые столы, прессконференции, экскурсии, сказки, репортажи [4].

Стоит отметить, что эффективность реализации интерактивных технологий, в первую очередь, зависит от педагога, его компетентности и профессиональных навыков. Действительно, именно грамотная организация поможет добиться желаемых результатов, следовательно, педагогу необходимо придерживаться определен- ных требований при организации рабочего процесса.

Подводя итог, можно сделать вывод, что интерактивное обучение способствует формированию эмоциональных контактов между учителем и учащимися, реализует воспитательные задачи, так как прививает навыки работы в команде или группе, учит уважать мнение своих товарищей по команде. Кроме этого, интерактивные технологии обеспечивают высокий уровень мотивации, прочность знаний, творческий подход, коммуникабельность, а также формирование активной жизненной позиции, понимание ценности индивидуальности, стремления к самовыражению, взаимоуважению и демократичности. Стоит отметить роль данных технологий в снижении нервной и психологической нагрузки обучающихся, возможности смены видов и форм деятельности, переключения внимания на основные моменты занятия.

Таким образом, благодаря интерактивному обучению возможно разрешить несколько задач одновременно, основная из которых - развитие коммуникативных умений и навыков. На современном этапе развития школьного образования интерактивные технологии становятся одним из важнейших инструментов перестройки учебной деятельности, основной целью которого является стимулирование и поддержка взаимодействия обучающихся и учителя, а также учеников между собой.

\section{ЛИТЕРАТУРА}

1. Антощенко, Е.Ю. Технологии интерактивного обучения иностранному языку и их характеристика / Е.Ю.Антощенко //Актуальные проблемы романо-германской философии и преподавания европейских языков в школе и вузе. - Марийский государственный университет. - 2017. - №4. - С. 114-119. URL: https://www.elibrary.ru/item.asp?id=30681505 (дата обращения: 25.08.2020).

2. Ахметова, М.Х. Применение интерактивных методов в обучении географии в школе / М.Х. Ахметова, Р.Р. Галиев // Материалы региональной научнопрактической конференции «Естественно-географические знания в современном образовательном пространстве школы и вуза». - Казань: Вестфалика. - С.15-18.

3. Биндас, 0.Б. Интерактивные технологии обучения / 0.Б.Биндас // Материалы 1 0ткрытого Всероссийского форума преподавателей иностранного языков «Иностранные языки - новому поколению профессионалов». - Йошкар-Ола: Издательство Поволжский государственный технологический университет, 2019. - C.140-149.

4. Данина Е.В. Современные технологии и методы обучения на уроках английского языка / Е.В. Данина // Материалы Всероссийской (национальной) научно-практической конференции «Теория, методика обучения и воспитания в современном образовательном пространстве». - Волгоград, 2019. C.63-67. - URL:https://elibrary.ru/item.asp?id=37574243 (дата обращения: 07.09.2020).

5. Магсумов Т.А. Интерактивные методы обучения истории и географии в педагогическом вузе / Т.А. Магсумов, М.Х. Ахметова // В сборнике: Право, история, педагогика и современность. Сборник статей Международной научно-практической конференции. 2020. - С. 81-85.

6. Панина, Т.С. Современные способы активизации обучения / Т.С. Панина, Л.Н. Вавилова. - М.: Изд. Центр «Академия», 2008. - 176 с.

7. Примерная основная образовательная программа основного общего образования. - М.: Просвещение, 2015. - 559 с.

8. Хоменко, Э.Е. Современные интерактивные педагогические технологии в обучении на уроках английского языка / Э.Е. Хоменко // Материалы Международной научно-практической конференции «Парадигма аграрного образования в условиях цифровизации экономики» - Волгоград: Издательство Волгоградский государственный аграрный университет, 2019. - С.257-269.

9. Шевченко, Н.И. Интерактивные методы как условие интерактивного образования / Н.И. Шевченко // Интерактивное образование. - 2018. - № 1. C.15-21 - URL: https://elibrary.ru/item.asp?id=34968815 (дата обращения: 07.09.2020).

10. Щемелева, И.Ю. Применение инновационных методов обучения иностранным языкам в школе: учебно-методическое пособие / И.Ю. Щемелева, Ю.С. Васильева, А.О. Наследова, И.В. Нужа. - Орск : Издательство ОГТИ, 2009.

11. Magsumov T.A. Family and school in Russia at the beginning of the 20th century: attempts to bridge the gap // European Journal of Contemporary Education. - 
2017. - T. 6. № 4. - C. 837-846.

12. Magsumov T.A. Ideas and meanings of symposium of historians of Russian education // Журнал министерства народного просвещения. - 2015. - № 4 (6). - C. 143-145. D0l: 10.13187/zhmnp.2015.6.143

13. Magsumov T.A. Periodicals as a source on the history of secondary vocational schools of late imperial Russia // Журнал министерства народного просвещения. 2014. - № 1 (1). - C. $12-20$.

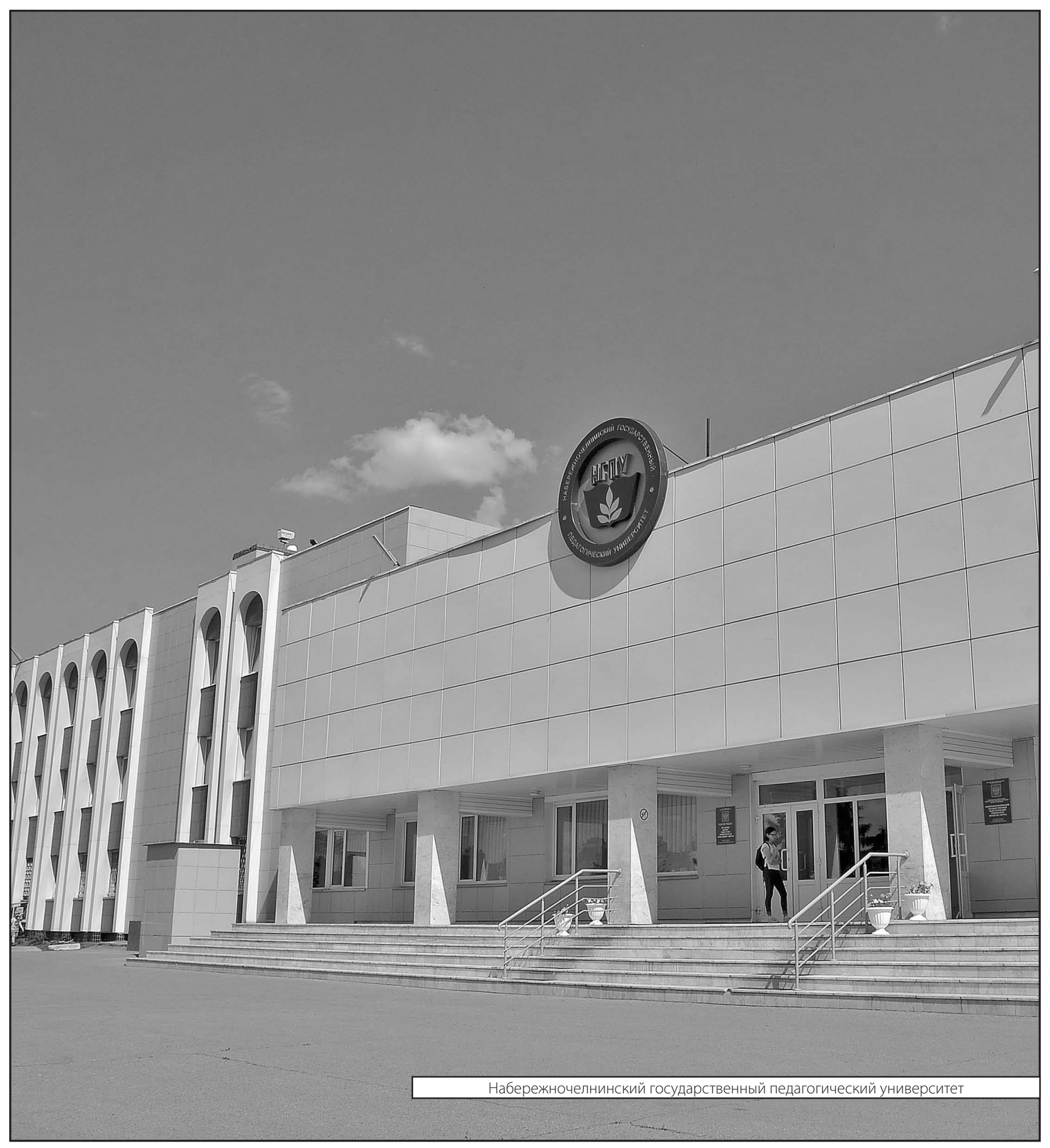

